\title{
Ergative case assignment in Hindi-Urdu: Evidence from light verb compounds
}

\author{
Yash Sinha*
}

\begin{abstract}
Various accounts have been proposed for ergative/absolutive case-assignment in Hindi-Urdu (HU) within the Minimalist Program. (Ura 2006, Anand \& Nevins 2006 etc.) Using facts about subject case-assignment in a particular type of light verb compound in $\mathrm{HU}$ as evidence, I propose a syntactic account for subject case-assignment in the language in general. This account relies on two claims: (i) absolutive case can be assigned by some I, V and $v$ heads to the subject, or (in the case of v) to the object, and (ii) ergative case results from a special KP configuration, only grammatical when absolutive case cannot be assigned to the subject. I show that this proposal can also explain facts about verb agreement in the language.
\end{abstract}

Keywords. Hindi; Urdu; ergativity; compound verb; light verb; case assignment

1. Introduction. Hindi-Urdu is a split-ergative language. The split is along the the lines of aspect, with ergative marking only occurring in the perfective. Various accounts have been proposed for ergative/absolutive case-assignment in Hindi-Urdu within the Minimalist Program (Ura 2006, Anand \& Nevins 2006 etc.)

In this paper, I will look at the distribution of ergative and absolutive case on subjects in a specific kind of compound verb that uses light verbs. I will use the facts about subject case assignment in light verb compounds to propose a new account for ergative/absolutive case assignment in the language within the Minimalist Program.

Most accounts of ergative/absolutive languages focus on accounting for the distribution of ergative case, leaving the absolutive case for those subjects that do not receive ergative case. My proposal differs from those accounts in that I first account for the distribution of absolutive case on subjects, and then show why ergative case occurs on those subjects that cannot receive absolutive case. The reason I do so is because, as I will show, the data from light verbs indicate that specific lexical items are consistently associated with absolutive case on subjects, but no such items exist for ergative case. Therefore, it is best to treat absolutive case as being assigned by specific items, and to treat ergative as a case occurring on those subjects that cannot receive absolutive case. Note, however, that I do not treat ergative as a last-resort or default case.

My proposal makes two separate claims: (i) absolutive case can be assigned by some I, V and $v$ heads to the subject, or (in the case of $v$ ) to the object, and (ii) ergative case results from a special KP configuration, only grammatical when absolutive case cannot be assigned to the subject. I will show how using these claims, we can explain ergative and absolutive case assignment in light verb compounds. This proposal is also able to account for case-assignment in verbs outside of light verb compounds, for the aspect split, and for the facts about verb agreement.

This paper is structured as follows. In Section 2, I will discuss the basics of ergativity in Hindi-Urdu, with an emphasis on how different classes of verbs interact with it. In Section 3, I

*I would like to thank Karlos Arregi for his mentorship throughout my work on this project. I would also like to thank the anonymous reviewers and the attendees at LSA 2017 Annual Meeting. Author: Yash Sinha, University of Chicago (yashsinha@uchicago.edu) 
will briefly introduce what light verbs are, and illustrate the facts about how ergativity interacts with light verbs. Then, drawing from the facts in Section 3, I will present my analysis for absolutive case assignment, and ergative case assignment in sections 4 and 5 respectively. In Section 6, I will cover the issue of verb agreement. Section 7 deals with the remaining issues in this analysis, and Section 8 concludes the paper.

2. Ergativity in Hindi-Urdu. To recapitulate, in Hindi-Urdu, subjects can show ergative marking in the perfective. In the non-perfective, the subject is never ergative. It takes absolutive case, as shown in (1).

$\begin{array}{llll}\text { raam } & \text { ghar } & \text { bec-taa } & \text { hai } \\ \text { Ram[ABS] } & \text { house[ABS] } & \text { sell-IPFV.M } & \text { AUX.PRES.3SG. } \\ \text { 'Ram sells houses.' } & & \end{array}$

Though I do present an account of the aspect split, much of this paper will only deal with the perfective since the perfective shows more variation with respect to case marking on the subject. From this point onwards, assume that this discussion is only concerned with verbs in the perfective, unless stated otherwise.

Ergative case on a subject is expressed by the enclitic -ne that attaches to the noun phrase. This contrasts with the absolutive case, which involves the noun phrase (the subject or the object) occurring as a bare form without any enclitic. Case marking also has ramifications for verb agreement, but the facts about agreement - and their analysis- are discussed separately in Section 6. I now turn to discuss which categories of verbs take ergative subjects, and which take absolutive subjects.

In the perfective, typically, intransitive verbs take absolutive subjects, while transitive verbs take ergative subjects, as in (2) and (3) respectively.

$\begin{array}{lll}\text { raam } & \text { ga-yaa } & \\ \begin{array}{ll}\text { Ram[ABS] } \\ \text { 'Ram went.' }\end{array} & \text { go-PFV.M } & \\ \text { raam=ne } & \text { ghar } & \text { khariid-aa } \\ \text { Ram=ERG } & \text { house[ABS] } & \text { buy-PFV.M } \\ \text { 'Ram bought the house.' } & \end{array}$

However, this is not true across the board. There are certain transitive verbs such as laanaa (to bring) that obligatorily take absolutive subjects, and some such as samajhnaa (to understand) that can take either absolutive or ergative subjects. (Kachru 1980: 63-64) This is shown in (4) and (5) respectively.

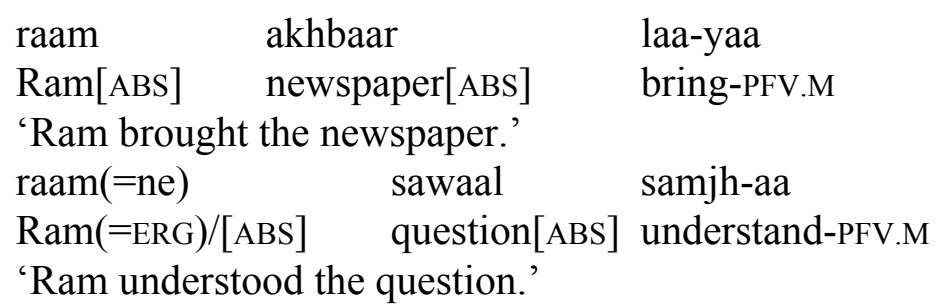

Moreover, some intransitive verbs such as "cough" or "scream", can also take both ergative and absolutive subjects. (Kachru 1980: 63-64). This is shown for khaaNsnaa (to cough) in (6). 


$$
\begin{array}{ll}
\operatorname{raam}(=\mathrm{ne}) & \text { khaaNs-aa } \\
\operatorname{Ram}(=\mathrm{ERG}) /[\mathrm{ABS}] & \text { cough-PFV.M } \\
\text { 'Ram coughed.' } &
\end{array}
$$

Based on their transitivity and their behaviour with respect to ergativity, I propose the classification of verbs shown in Table 1.

\begin{tabular}{ll} 
Name & Description \\
\hline Regular Intransitives & Most intransitives; they only take absolutive subjects \\
Cough-Intransitives & Intransitives that can take absolutive or ergative subjects \\
Regular Transitives & Most transitives; they only take ergative subjects \\
Bring-Transitives & Transitives that only take absolutive subjects \\
Understand-Transitives & Transitives that can take absolutive or ergative subjects \\
\hline
\end{tabular}

Table 1: Classification of verbs based on transitivity and the case of their subject

3. Light verbs and ergativity. Light verb compounds involve a main verb, that is followed by a light verb. The main verb occurs as a bare stem, whereas the light verb is inflected for tense and aspect, and may show $\varphi$-feature agreement with the arguments of the compound verb. The event denoted by the compound verb is the event that the main verb ordinarily denotes. The light verb contributes additional semantic meaning, such as those of "completion, suddenness, directionality, benefaction, intensity, violence, stubbornness, reluctance, regret, forethought, thoroughness, etc." (Masica 2005:143) In this paper, the term "simple verb" will be used to contrast verbs when they occur on their own, as opposed to when they occur with light verbs.

Before proceeding to illustrate how light verbs interact with ergativity, I will introduce some terminology I will be using for the rest of the paper. Light verbs can be classified into two types, which I will call ERG and ABS light verbs. ERG lights verbs are those that take ergative subjects when they occur as simple verbs. They all also happen to be transitive. Examples of these verbs are denaa (to give), lenaa (to take) and maarnaa (to hit). On the other hand, ABS lights verbs are those that take absolutive subjects when they occur as simple verbs. They are all intransitive, and include verbs like aanaa (to come) and jaanaa (to go). Note that the words ABS and ERG are not based on the behaviour of these light verbs when they occur as light verbs. It refers to their behaviour when they occur as simple verbs.

By examining the case of the subject with these light verbs, three generalizations become clear. Firstly, regardless of what the main verb is, if the light verb is an ABS light verb, the subject will obligatorily take the absolutive case. This is illustrated for a regular intransitive in (7), for a cough-intransitive in (8), for a regular transitive in (9) and for an understand-transitive in (10). The light verbs jaanaa (to go) and paDnaa (to fall) in these sentences are ABS verbs.

$\begin{array}{lll}\text { raam } & \text { gir } & \text { ga-yaa } \\ \text { Ram[ABS] } & \text { fall } & \text { go-PFV.M } \\ \text { 'Ram fell.' } & & \end{array}$




$\begin{array}{llll}\text { raam } & \text { khaaNs } & \text { paD-aa } & \\ \text { Ram[ABS] } & \text { cough } & \text { fall-PFV.M } & \\ \text { 'Ram coughed.' } & & \\ \text { raam } & \text { kitaab } & \text { le ga-yaa } \\ \text { Ram[ABS] book[ABS] } & \text { take go-PFV.M } \\ \text { 'Ram took the book.' } & & \\ \text { ram } & \text { baat } & \text { samajh } & \text { ga-yaa } \\ \text { Ram[ABS] matter[ABS] } & \text { understand } & \text { go-PFV.M } \\ \text { 'Ram understood the matter.' } & \end{array}$

The second generalization is that with the exception of understand-and bring-transitives, all other verbs take the same subject case with ERG light verbs as the one they take as simple verbs. For example, regular intransitives take only absolutive subjects as simple verbs, and so with ERG light verbs, they only take absolutive subjects. This is shown in sentence (11), taken from Mahajan (2012), where the verb denaa (to give) is an ERG light verb.

$$
\begin{array}{ll}
\text { Mahajan (2012) } & \\
\text { gaaDii col d-ii } \\
\text { train[ABS] move } & \text { give-PFV.F } \\
\text { 'The train moved.' } &
\end{array}
$$

Similarly, since cough-intransitives can take either absolutive or ergative subjects as simple verbs, they can also take absolutive or ergative subjects with ERG light verbs, as illustrated in (12).

$\begin{array}{lll}\operatorname{raam}(=\mathrm{ne}) & \text { khaaNs } & \begin{array}{l}\text { di-yaa } \\ \text { give-PFV.M }\end{array} \\ \text { 'Ram coughed.' } & \text { cough } & \text { giva } /[\mathrm{ABS}]\end{array}$

In the same vein, regular transitives only take ergative subjects when they occur with ERG light verbs, as depicted in (13).

$\begin{array}{llll}\text { raam }=\text { ne } & \text { ghar } & \text { de } & \text { di-yaa } \\ \text { Ram=ERG house[ABS] } & \text { give } & \text { give-PFV.M } \\ \text { 'Ram gave the house.' } & & \end{array}$

Before moving to the third generalization, I want to highlight how these two generalization will motivate my analysis. These two generalizations imply that ABS light verbs are consistently associated with absolutive case on subjects, but ERG light verbs are not consistently associated with ergative case. This is similar to how the non-perfective is consistently associated with absolutive case (since subjects obligatorily receive absolutive case in the non-perfective), but the perfective is not necessarily associated with ergative case (since subjects do not always receive ergative case in the perfective). Both of these points suggest that specific items such as non-perfective inflection or ABS light verbs are responsible for the absolutive case on subjects, whereas ergative case results from some other process, that is operational only when these items are not present.

Coming to the third generalization, as Mahajan (2012) notes, non-regular transitive verbs that do not obligatorily take ergative subjects as simple verbs, must obligatorily take ergative subjects 
when combined with what I have termed ERG light verbs, Hence, the third generalization is that the non-regular behaviour of understand- and bring- transitives is only limited to when they occur as simple verbs. When they occur with light verbs, they behave like any other transitive verb. When they occur with an ERG light verb, they necessarily take an ergative subject, just like regular transitives. This is shown for "bring" in (14). When they occur with an ABS light verb, they necessarily take an absolutive subject. This is shown for "understand" in (15).

\begin{tabular}{|c|c|c|c|c|}
\hline \\
\hline \multicolumn{5}{|c|}{$\begin{array}{l}\text { Mahajan (2012) } \\
\text { kabiir=ne vo }\end{array}$} \\
\hline Kabir $=$ ERG & that[ABS] & book[ABS] & bring & $\begin{array}{l}\text { d-1l } \\
\text { give-PFV.F }\end{array}$ \\
\hline \multicolumn{5}{|c|}{ 'Kabir brought that book.' } \\
\hline \multicolumn{5}{|c|}{ Mahajan (2012) } \\
\hline vo & yah & baat & samajh & ga-yaa \\
\hline he[ABS] & this [ABS] & matter[ABS] & understand & go-PFV.M \\
\hline
\end{tabular}

The three generalizations are summarised in Table 2. The second column ("As simple verbs") shows the case the subject takes when the verb occurs as a simple verb. The third and fourth column show the case the subject takes when these verbs occur with ERG and ABS light verbs respectively.

\begin{tabular}{llll} 
& As simple verbs & $\begin{array}{l}\text { With ERG light } \\
\text { verbs }\end{array}$ & $\begin{array}{l}\text { With ABS light } \\
\text { verbs }\end{array}$ \\
\cline { 2 - 4 } Regular Intransitives & Absolutive & Absolutive & Absolutive \\
Regular Transitives & $\begin{array}{l}\text { Ebsolutive/ } \\
\text { Ergative }\end{array}$ & Absolutive/ Ergative & Absolutive \\
Understand-Transitives & $\begin{array}{l}\text { Absolutive/ } \\
\text { Ergative }\end{array}$ & Ergative & Absolutive \\
Bring-Transitives & Absolutive & Ergative & Absolutive \\
\hline
\end{tabular}

Table 2: Summary of interaction of light verbs with subject case assignment

4. Absolutive case assignment. As I noted above, non-perfective inflection and ABS light verbs are consistently associated with absolutive case assignment on subjects. Therefore, I claim that they are responsible for the assignment of absolutive case. In this section, I show how three different syntactic heads (including the heads corresponding to non-perfective inflection and ABS light verbs) can assign absolutive case to DPs. My proposal for absolutive case assignment is as follows.

Absolutive case can be assigned by some (but not all) varieties of inflectional heads (I), light verb heads (V2) or by little $v$. Moreover, little $v$ is also capable of assigning absolutive case to the object. Here, I am arguing, contra Legate (2008) and others, that the absolutive case in Hindi-Urdu on subjects and objects is the same abstract case, and that case can be assigned by 
some I, V2 or $v$ heads. The absolutive case assigning heads are also $\varphi$-probes, and value their $\varphi$-features from the DPs they assign case to. The case-assignment and $\varphi$-feature valuation take place via Cyclic Agree (Béjar \& Rezac 2009). This means that the case assigning head Agrees with the closest DP in its c-command domain. If no such DP exists, it looks to the DP in its specifier to Agree with.

Not all I, V2 and $v$ heads can assign absolutive case. Some of these heads are defective: they do not assign absolutive case, and are also not $\varphi$-probes. In particular, $\mathrm{I}_{\text {perf }}$ (inflectional head that occurs with the perfective) and $\mathrm{V} 2_{\text {erg }}$ (corresponding to ERG light verbs) are not case assigning. Moreover, I also posit that there is a defective little $v\left(v_{\text {def }}\right)$, that can optionally occur with cough-intransitives. This $v_{\text {def }}$ is also not case assigning. The regular, non-defective $v$ will be referred to as $v_{\text {reg. }}$ Focussing specifically on the I head, the claim that $\mathrm{I}_{\text {perf }}$ is not a phi-probe, and that $I_{\text {non-perf }}$ is a phi-probe, is in line with similar claims made about Neo-Aramaic (Kalin \& van Urk 2014) and Kutchi (Keine, Nissar \& Bhatt 2014).

All of these facts can account for the distribution of absolutive case in the data presented earlier. First, let us consider simple verbs in the perfective. For regular intransitive verbs, $v_{\text {reg }}$ assigns absolutive case (depicted by the word ABS) to the subject because there is no object to assign this case to. This is illustrated in $(16)^{2}$ for an unergative verb. The blue line indicates Cyclic Agree between $v_{\text {reg }}$ and the external argument. For unaccusative, intransitive verbs, we also get absolutive case on the subject, because in these verbs, there is Cyclic Agree between $v_{\text {reg }}$ and the internal argument. Hence, all regular intransitives take absolutive subjects.

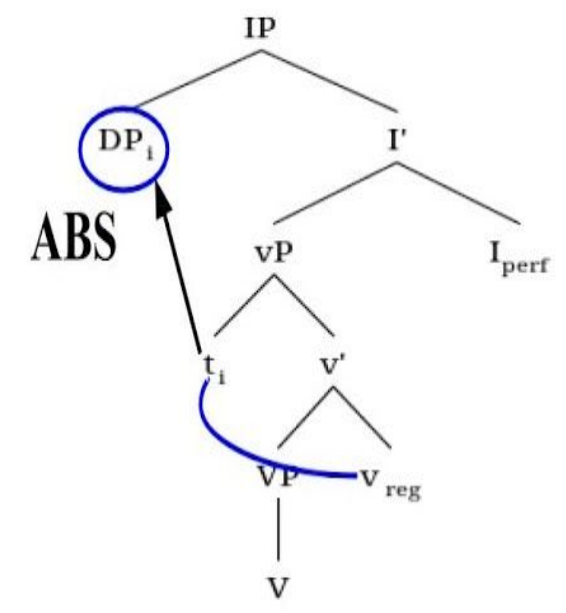

For regular transitive verbs in the perfective, the subject gets ergative case. We will consider how ergative case is assigned in the next section, but for now, it suffices to say that subjects get ergative case if and only if they cannot be assigned absolutive case. The reason that the subject of a regular transitive verb does not get absolutive case in the perfective is because little $v$ assigns case to the object of the verb. Given that $\mathrm{I}_{\text {perf }}$ is not case assigning, there is nothing to assign absolutive case to the subject.

\footnotetext{
${ }^{2}$ The movement of the DP from Spec, $v$ to Spec, I occurs to satisfy the Extended Projection Principle and is irrelevant for our account.
} 
Cough-intransitives can optionally take ergative subjects. To allow for this, I propose that these verbs can either be selected by a regular case-assigning $v$, or by non-case assigning $v_{\text {def. }}$ In this analysis, $v_{\text {def }}$ can only occur with cough-intransitives, and not with any other verb. When cough-intransitives take regular $v$, they behave like other intransitive verbs and take absolutive subjects. When they take $v_{\text {def }}$, they behave like transitive verbs because there is no head to assign absolutive case to the subject, and the subject appears with ergative case.

Before explaining the behaviour of bring-and understand- transitives, I will explain how light verbs can affect case assignment. Note that we are still only dealing with the perfective. Light verbs attach in between little $v$ and I, as we will see in (17)-(18) below.

Ignoring bring-and understand- transitives for now, we noted in the previous section that ERG light verbs do not affect case-assignment in any way. This follows from the fact that $\mathrm{V} 2_{\text {erg }}$ is not case assigning. In other words, the presence or absence of an ERG light verb ( $\mathrm{V} 2_{\text {erg }}$ ) has no effect on case-assignment, and case-assignment proceeds as if there were no light verb.

ABS light verbs, on the other hand, do have an effect on case-assignment. Specifically, if there is an ABS light verb, the subject always occurs in the absolutive case. This follows from the fact that $\mathrm{V}_{\text {abs }}$ is not defective, and does assign absolutive case. So for transitive verbs (and optionally, for cough-intransitives), even though $v$ cannot assign absolutive case to the subject, the subject still gets absolutive case from $\mathrm{V} 2$ abs. This is illustrated in (17), where the object is assigned absolutive case by $v_{\text {reg }}$, and the subject is assigned absolutive case by $\mathrm{V} 2_{\text {abs. }}$

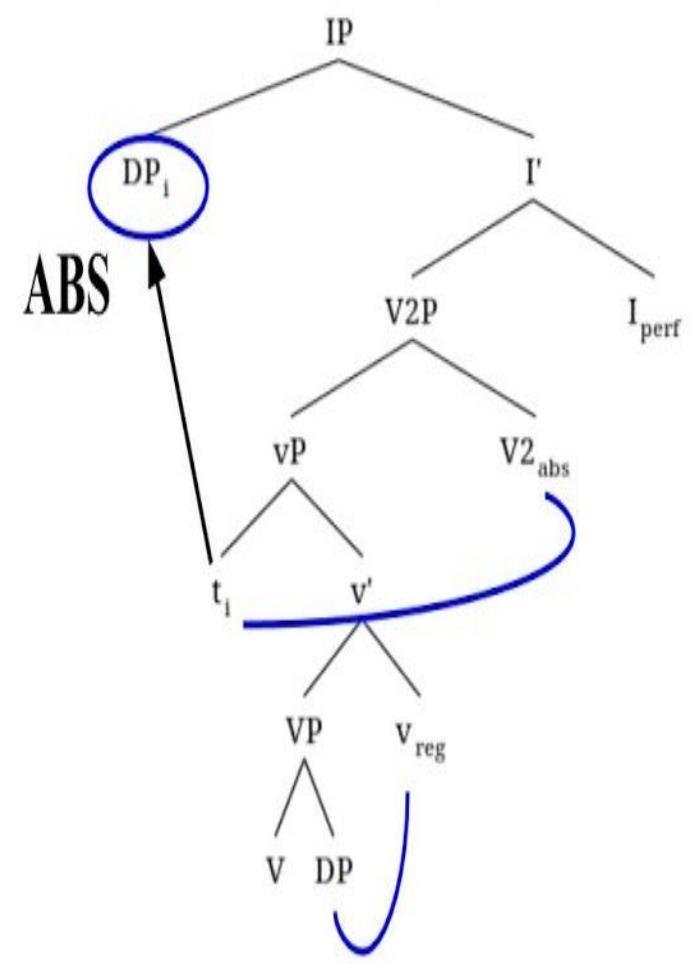

For intransitive verbs with $\mathrm{ABS}$ light verbs, both $\mathrm{V} 2_{\text {abs }}$ and $v$ assign absolutive case to the subject. For this to be possible, we have to assume that the Activity Condition (Chomsky 2000, 
2001) does not apply in Hindi-Urdu. Case assignment for intransitive verbs with ABS light verbs in the perfective is illustrated in (18).

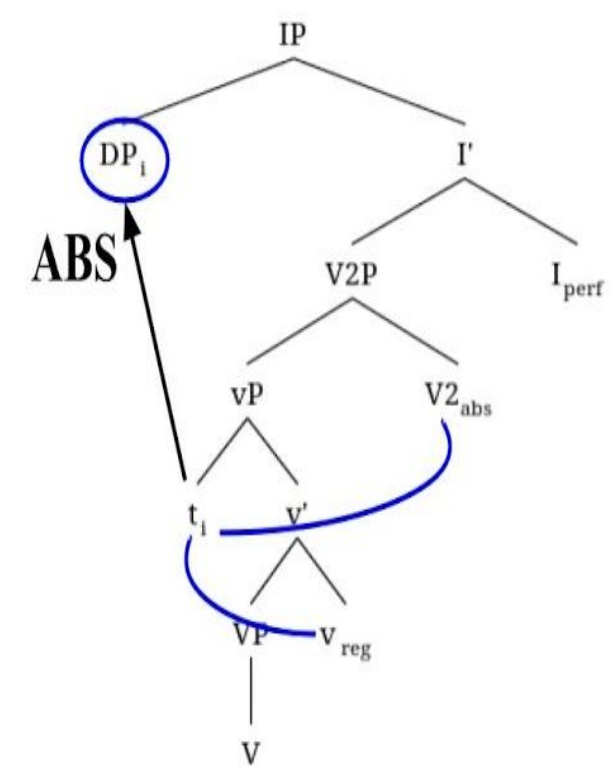

Hence, $\mathrm{V} 2_{\text {abs }}$ assigns absolutive case to the subject regardless of what happens lower in the tree. We can also use this behaviour of $\mathrm{V}_{\text {abs }}$ to explain the facts about bring- and understandtransitives. Bring-transitives obligatorily, and understand-transitives optionally take an invisible $\mathrm{V}_{\text {abs }}$. As such, these verbs behave like a transitive verb followed by an ABS light verb, and the subject gets absolutive case (see (17) above).

This invisible $\mathrm{V} 2_{\text {abs }}$ is only present when these verbs occur as simple verbs. When they occur with other light verbs, the invisible $\mathrm{V} 2_{\text {abs }}$ is replaced with a regular $\mathrm{V}_{\text {abs }}$ or $\mathrm{V} 2_{\text {erg }}$, depending on whether the light verb is ABS or ERG. Then, their structure is identical to any other transitive verb with a light verb. Therefore, with light verbs, these verbs pattern exactly like other transitive verbs.

The invisible $\mathrm{V} 2_{\text {abs }}$ might seem like an arbitrary stipulation, but there is at least some diachronic motivation for it for the verb laanaa (to bring). This verb derives from the compound le aanaa (take + come), which is similar in structure to a light verb construction. (Forbes 1855:104) Moreover, the verb aanaa (to come) is an ABS light verb. Historically, this means that laanaa had the exact same structure as a transitive main verb, followed by an ABS light verb. Therefore, I have posited that the structure for bring-transitives, when they occur as simple verbs, is the same as that of a transitive main verb, followed by an ABS light verb.

Case assignment in the non-perfective can also easily be explained. Just like $\mathrm{V} 2_{\text {abs }}$ can always assign absolutive case to the subject, regardless of what happens lower in the tree, $\mathrm{I}_{\text {non-perf }}$ is also case assigning, and can assign absolutive case to the subject, regardless of what happens lower in the tree. This is why, we always see an absolutive subject in the non-perfective, regardless of the presence or absence of a light verb, or the transitivity of the main verb. 
5. Ergative case assignment. Now let us turn our attention to the assignment of ergative case. I have so far maintained that ergative case is assigned to a subject DP if and only if absolutive case cannot be assigned to it. This could either be because there is no absolutive case assigning head in the derivation, or because the only absolutive case assigning head assigns case to the object.

It would seem like ergative case is some kind of default or last-resort case. However, in the current analysis, I do not make reference to any kind of default or last-resort case assignment. Instead, I propose that the ergative case results from a KP configuration. The existence of a $\mathrm{K}$ head that is an exponent of case marking has been proposed by Lamontagne \& Travis (1987), and Bittner \& Hale (1996), among others. I sketch out my KP analysis of the Hindi-Urdu ergative case below.

DPs that appear with ergative case originate in a KP configuration. The KP consists of a $\mathrm{K}$ head that takes as its complement, a DP, as shown in (19). Moreover the K head assigns abstract case to the DP, which is depicted with the red line in (19) below.

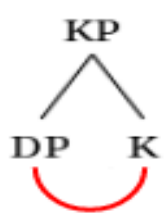

The ergative (along with other cases such as the dative and genitive) in Hindi-Urdu involves an enclitic that attaches to the last element of the DP. In non-absolutive cases, the DP takes the oblique form, that may or may not be different from the absolutive form. Given below, in Table 3 is the paradigm for laDkaa (boy), which does show such an absolutive/oblique opposition.

\begin{tabular}{lll} 
& Singular & Plural \\
\hline Absolutive Case & laDkaa & laDke \\
Oblique Cases & $\begin{array}{l}\text { laDke }=k o \text { (dative), ladke=ne } \\
\text { (ergative) }\end{array}$ & $\begin{array}{l}\text { laDko }=k o \text { (dative), ladk } \tilde{o}=n e \\
\text { (ergative) }\end{array}$ \\
\hline
\end{tabular}

Table 3: Case paradigm for laDkaa (boy)

As such, the case that is assigned by the $\mathrm{K}$ head to its DP complement is not the more composite ergative case, but rather, the oblique case (which contrasts with the absolutive case). The ergative clitic is the realization of the $\mathrm{K}$ head. While this paper only deals with ergative case, I believe that a similar KP-based proposal could be made regarding the composition of other oblique cases. We would have to propose different $\mathrm{K}$ heads, each head corresponding to a particular oblique case.

The case-assigning property of $\mathrm{K}$ can account for why ergative DPs are grammatical when no I, $\mathrm{V} 2$ or $v$ head is available to assign case to the subject. This is because the ergative DPs already have their case assigned by the $\mathrm{K}$ head. For example, consider how the subject of a cough-intransitive can optionally be ergative, if the verb occurs as a simple verb. Here, the verb 
can optionally occur with $v_{\text {def }}$, which cannot assign absolutive case to the subject. A KP (that is, an ergative marked DP). however, is grammatical in this situation, as we can see in (20).

(20)

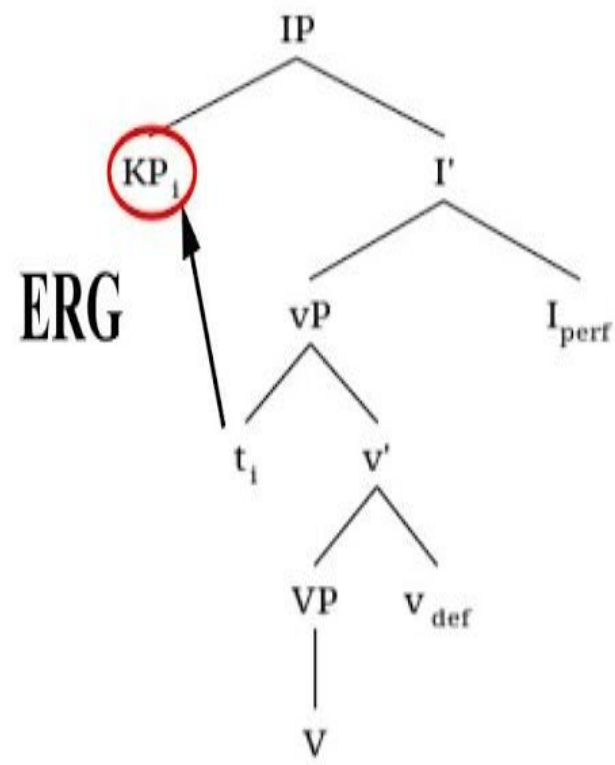

Similarly, in (21), we see why regular transitives, as simple verbs, also take ergative subjects. Here, even though $v_{\text {reg }}$ is case-assigning, this case is assigned to the object instead of the subject, making absolutive case on the subject ungrammatical. Once again, the KP is grammatical.

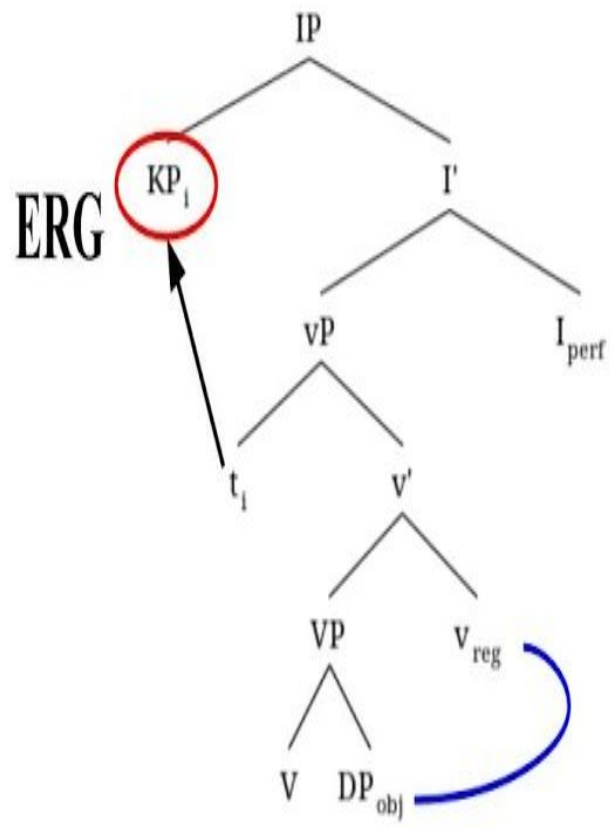


A KP analysis of Hindi-Urdu cases has also been proposed by Butt \& King (2004) for Hindi-Urdu. However, the current analysis differs from Butt \& King's analysis in one crucial way. While they propose that DPs in the absolutive case also project a KP, albeit without an overt $\mathrm{K}$ head, I propose that absolutive DPs do not have a KP projection. This is why absolutive DPs need at least one I, V2 or $v$ head to assign (absolutive) case to them.

While we have established why ergative subjects can appear when absolutive subjects cannot, we also need to account for why ergative subjects do not appear when absolutive subjects can. In other words, our analysis should not overgenerate ergative subjects. To do this, I also propose that KP is a phase. Recall that under the current analysis, the absolutive case assigning I, $v$ and V2 heads are also $\varphi$-probes. I am claiming that if they fail to value their $\varphi$-features, the derivation crashes. If KP is a phase, by the Phase Impenetrability Condition (Chomsky 2000), any absolutive case assigning I, $v$ or V2 head cannot probe the DP inside a KP for valuing its $\varphi$-features. This means that ergative marked DPs are unavailable to these absolutive case assigning probes. If the $\varphi$-features of these probes are not valued, the derivation crashes, leading to ungrammaticality. Hence, ergative subjects are ungrammatical in structures where absolutive subjects are grammatical.

At this point, one may ask why the absolutive case assigning I or V2 cannot probe an absolutive object for $\varphi$-features. For example, a non-perfective I, $I_{\text {non-perf }}$ could probe the object for $\varphi$-features. Since we are not assuming the Activity Condition, the fact that $v$ also probes the object for $\varphi$-features is irrelevant. This would predict that ergative subjects are grammatical with non-perfective, transitive verbs. This prediction is obviously not borne out.

There is however a straightforward explanation for why I or V2 cannot probe an absolutive object for $\varphi$-features. That is because, like KP, $v \mathrm{P}$ is also a phase, and since the object is inside the $v \mathrm{P}$, and I and V2 outside, these two heads cannot probe the object for $\varphi$-features.

Finally, we also need to restrict ergative DPs to external arguments. So far, nothing about this analysis prevents objects of transitive verbs from having ergative case, if the absolutive case-assigning heads Agree with the subject (and assign absolutive case to it). In other words, we could have sentences where the subject is absolutive and the object is ergative. This is certainly not the case in Hindi-Urdu. Therefore, to restrict ergative DPs to external arguments, I propose that the ergative $\mathrm{K}$ head can only adjoin the tree at Spec, $v$. The reason that ergative DPs cannot be generated as objects is because $\mathrm{V}$ does not select for an ergative $\mathrm{K}$ complement.

6. Agreement. So far, this paper has only explicitly talked about case assignment. However, in Hindi-Urdu, verb agreement is closely linked to case. Verbs show agreement with the highest absolutive argument. This means that if the subject appears in the absolutive case, the verb agrees with the subject, as in (22), where the verb agrees with the feminine subject, "Sita".

$\begin{array}{lll}\text { siitaa } & \text { aam } & \text { laa-yii } \\ \text { Sita(F)[ABS] } & \text { mango(M)[ABS] } & \text { bring-PFV.F } \\ \text { 'Sita brought a mango/mangoes.' } & \end{array}$

If the subject is not in the absolutive case, then the verb agrees with the object, provided that the object is in the absolutive case. This is shown in (23), where the verb agrees with the object, "vegetable", which is grammatically feminine and not with the ergative subject, "Ram", which is 
masculine.

$$
\begin{array}{lll}
\text { raam }=\text { ne } & \text { sabzii } & \text { khaa-yii } \\
\operatorname{Ram}(M)=\text { ERG } & \text { vegetable(F)[ABS }] & \text { eat-PFV.F } \\
\text { 'Ram ate vegetables.' } &
\end{array}
$$

It is also possible that neither the subject, nor the object is absolutive. This may happen when the subject takes ergative case marking, and the object takes Differential Object Marking (DOM). In these cases, the verb does not agree with either of the arguments, and shows default singular, masculine agreement. In (24), the subject and the object are both feminine names, yet the verb shows default masculine agreement.

$$
\begin{array}{lll}
\text { siitaa }=\text { ne } & \text { giitaa=ko } & \text { dekh-aa } \\
\text { Sita(F)=ERG } & \text { Gita(F)=DOM } & \text { see-PFV.M } \\
\text { 'Sita saw Gita.' } &
\end{array}
$$

Recall that whichever head assigns absolutive case to a subject or object DP also values its $\varphi$-features from that DP. As such, agreement is the result of the $\varphi$-features on I, V2 and/or $v$ heads, and the post-syntactic rules that govern their interaction. I will not detail what these post-syntactic rules are, but they must be such that:

1. The $\varphi$-features on $v$ are deleted if some higher head (V2 or I) also has $\varphi$-features.

2. If there are no $\varphi$-features on I, V2 or $v$, then we get default agreement.

Therefore, if the subject is absolutive, then I, V2 and/or $v$ would have its $\varphi$-features, and no higher head would have $\varphi$-features of a different DP. As a result, in these cases, subject agreement occurs. If the subject is not absolutive, then I and V 2 cannot have any $\varphi$-features because the subject is the only DP they can value $\varphi$-features from. In these cases, if the object is absolutive, $v$ has its $\varphi$-features and $v$ is the highest head with any $\varphi$-features, resulting in object agreement. If the object also is not absolutive, then I, V2 and $v$ all do not have $\varphi$-features, and we get default agreement on the verb.

7. Remaining issues. The proposed analysis of case assignment and agreement in Hindi-Urdu leaves two issues unresolved. The first is the problem with Differential Object Marking (DOM). The DOM marker - $k o$ occurs obligatorily on animate nouns, and optionally on inanimate nouns. When it occurs with inanimate nouns, it leads to a specific reading. (Kachru 1980)

Note the following two facts about DOM objects. Firstly, as previously mentioned, DOM objects do not trigger agreement on the verb. This makes it unlikely that $v$ probes the DOM object for $\varphi$-features, given that in this analysis, agreement is a direct consequence of probing. Secondly, the structure of a DOM object is the same as an ergative subject. That is, it involves a DP in the oblique case, followed by the DOM clitic, $-k o$. As such, DOM should also involve a KP configuration, making it unlikely that $v$ assigns case to this object.

This means that when there is a DOM object, $v$ should be available to assign absolutive case to the subject, regardless of whether I or V2 can do so. This would make absolutive subjects grammatical with DOM objects, even if they are ungrammatical in sentences that are otherwise the same, but have an absolutive object instead of a DOM object.

The ungrammaticality of (25) shows that this prediction is not borne out. This sentence is grammatical when the subject takes the ergative (as in (24) above), but not when the subject is 
absolutive. As the current analysis predicts that (25) should be grammatical, this is an issue.

$\begin{array}{lll}\text { *siitaa } & \text { giitaa=ko } & \text { dekh-ii } \\ \text { Sita[ABS] } & \text { Gita=DOM } & \text { see-PFV.F } \\ \text { 'Sita saw Gita.' } & \end{array}$

Another problem that is associated with this analysis is that subjects of many intransitive verbs in infinitival clauses cannot occur in the absolutive case, and must take the genitive case. Consider (26) below.
raam $=\mathrm{kaa}$
so-naa
galat hai
Ram $=$ GEN
sleep-INF
wrong be.PRES.3SG.
'It is wrong for Ram to sleep.'
', (Literally: "Ram's sleeping is wrong")

Even if we say that $I_{\text {non-finite }}$ does not assign absolutive case to the subject, under our current analysis, the subject of an intransitive verb can receive absolutive case from $v$. There is no reason to posit that the $v$ in infinitival clause is different from the $v$ in a finite clause. Hence, our analysis cannot capture the ungrammaticality of sentences like (27), because the subject of the infinitival clause should be able to receive absolutive case under the current analysis.

$$
\begin{aligned}
& \text { *raam so-naa galat hai } \\
& \text { Ram[ABS] sleep-INF wrong be.PRES.3SG. } \\
& \text { 'It is wrong for Ram to sleep.' }
\end{aligned}
$$

While addressing these two issues is beyond the scope of this paper, it is important to highlight that a complete analysis of case assignment and agreement in Hindi-Urdu must also address them. Therefore, the analysis presented here cannot be the complete picture.

8. Conclusion. In this paper, I have proposed an analysis for the facts about ergative and absolutive case assignment in Hindi-Urdu. The focus of this paper has been to account for the data from light verbs discussed by Mahajan (2012). Evidence from light verbs shows that certain lexical items (such as ABS light verbs) are consistently associated with absolutive case, which suggests that this case is assigned by those items. Further, light verbs demonstrate that ergative case cannot consistently be associated with particular items, and is therefore best treated as occurring on those subjects, which cannot be assigned absolutive case. This insight gained by examining the data from light verbs led to an analysis that can also explain case assignment in simple verbs, the aspect split and the facts about agreement.

This analysis made two separate claims. The first is that absolutive case is assigned by $\mathrm{I}_{\text {non-perf }}$, $\mathrm{V} 2_{\mathrm{abs}}$ and $v$ to the subject and (in the case of $v$ ) to the object, via Cyclic Agree. The second is that ergative case results from a KP configuration. This account of ergative case is unconventional in that under this account, the DP itself does not receive ergative case. Rather, it receives oblique case, and it does so from $\mathrm{K}$. The so-called ergative case is actually more complex than the absolutive/oblique cases.

This is different from the accounts of ergative case in Hindi-Urdu in which it is a structural case assigned by a head such a $v$ or I. However, I have also not proposed that ergative case is an inherent case. Its distribution is not motivated by a particular theta role. Rather, different principles such as the need for DPs to receive case, the fact that case-assigning I, $v$ and V2 heads 
are $\varphi$-probes, and the Phase Impenetrability Condition, interact in a way that makes ergative subjects grammatical in some cases, and absolutive subjects grammatical in others.

Despite all its explanatory powers, this analysis also raises at least two issues. These have to do with Differential Object Marking, and the case of the subject in infinitival clauses. These issues are beyond the scope of this paper, and I leave them for future research.

\section{References.}

Anand, Pranav \& Andrew Nevins. 2006. The Locus of Ergative Case Assignment: Evidence from Scope. Studies in Natural Language and Linguistic Theory. 3-25. https://dx.doi.org/10.1007/1-4020-4188-8_1.

Bittner, Maria \& Ken Hale. 1996. The structural determination of Case and agreement. Linguistic Inquiry 27. 1-68.

Béjar, Susana \& Milan Rezac. 2009. Cyclic Agree. Linguistic Inquiry 40(1). 35-73. https://dx.doi.org/10.1162/ling.2009.40.1.35.

Butt, Miriam \& Tracy Holloway King. 2004. The Status of Case. Clause Structure in South Asian Languages Studies in Natural Language and Linguistic Theory. 153-198.

https://dx.doi.org/10.1007/978-1-4020-2719-2_6.

Chomsky, Noam. 2000. Minimalist inquiries: the framework. In Step by step. Essays on minimalist syntax in honor of Howard Lasnik, ed. Roger Martin, David Michaels, and Juan Uriagereka, 89- 155. Cambridge, MA: MIT Press.

Chomsky, Noam. 2001. Derivation by phase. In Ken Hale: a life in language, ed. Michael Kenstowicz, 1-52. Cambridge, MA: MIT Press.

Forbes, Duncan. 1855. A grammar of the Hindustani language. London: W.H. Allen.

Kachru, Yamuna. 1980. Aspects of Hindi grammar. New Delhi: Manohar Publications.

Kalin, Laura \& Coppe van Urk. 2014. Aspect splits without ergativity. Natural Language \& Linguistic Theory 33(2). 659-702. https://dx.doi.org/10.1007/s11049-014-9262-8.

Keine, Stefan, Trupti Nisar \& Rajesh Bhatt. 2014. Complete and defective agreement in Kutchi. Linguistic Variation 14(2). 243-288. https://dx.doi.org/10.1075/lv.14.2.02kei.

Lamontagne, Greg \& Lisa Travis. 1987. The Syntax of Adjacency. WCCFL 6. 173-186.

Legate, Julie Anne. 2008. Morphological and abstract case. Linguistic Inquiry 39. 55-101. http://dx.doi.org/10.1162/ling.2008.39.1.55.

Mahajan, Anoop. 2012. Ergatives, antipassives and the overt light v in Hindi. Lingua 122(3). 204-214. http://dx.doi.org/10.1016/j.lingua.2011.10.011.

Masica, Colin. 2005. Defining a linguistic area: South Asia. New Delhi: Chronicle Books.

Ura, Hiroyuki. 2006. A Parametric Syntax of Aspectually Conditioned Split-Ergativity. Studies in Natural Language and Linguistic Theory. 111-141. https://dx.doi.org/10.1007/1-4020-4188-8 5. 